\title{
The Research of Uneven Educational Resources
}

\author{
Yina $\mathrm{Xu}^{1, *}$ \\ ${ }^{1}$ Chengyi College of Jimei University, Xiamen, Fujian Province, China, 361021 \\ *Corresponding author. Email: 2486376417@qq.com
}

\begin{abstract}
With the development of the economy and education industry, the competition between people has been intensified. However, that situation is caused by the problem of uneven distribution of educational resources, which seriously affects the opportunity of fair competition and children's equal right to education. The main objective of the paper is by evaluating and exploring the unequal access to educational resources and future development among different social situations to find out whether the current education system is capable of giving children the opportunities to acquire knowledge. By reading and studying the papers, data and researches the paper findings show an unequal distribution of educational resources, especially for higher education. The approaches of the paper are identifying and describing various aspects of the society, for instance, local education policy, the teaching level of teachers, teaching facilities, and parental income level, which have effects on social resources access and social equality. The significance of the paper is making people aware of this severe problem and implement relevant measures.
\end{abstract}

Keywords: economic globalization, distribution of educational resources, uneven development, rich and poor, society

\section{INTRODUCTION}

In recent decades, with the popularization and development of compulsory education, as well as the development of higher education, though high quality education resources are increasing, the competition for admission is more fierce. This competition gives rise to educational anxiety in China, and the root of this competition is the uneven distribution of educational resources. When it comes to big cities in China, such as Beijing, Shanghai, Guangzhou, Shenzhen, Nanjing and Hangzhou, the competition for school choice is extremely fierce, because the gap between the teaching quality of schools is gigantic. Obviously, parents manage to get their children into the best schools, which aggravates the pressure on children's studying and the fierce competition situation. Hence, the paper is to dig out the reasons why the educational resources are uneven. One of the main goals of this research is bridging the gap of uneven educational resources between the poor areas and the rich areas, as well as the poor people and the rich people. What's more, it is crucial to enhance the efficiency of higher education, increase the quality of education and provide equal opportunities in education, especially for those groups with low educational resources. Some schools often seem to be either confronting the difficulties or absorbed in the tribulations of the present. As a result, we need to explore more about education policy, facilities, areas, teachers and backgrounds of children, making suggestions for future development and potential problems.

\section{ANALYSIS OF EMBODIMENT OF UNEVEN DISTRIBUTION OF EDUCATIONAL RESOURCES}

Statistics show that in the 20 years from 1978 to 1998, nearly 20 percent of Peking University's students came from rural areas. From 2000 to 2011, the proportion of rural students in Peking University was only about 10 percent[1]. Public opinion attributed this phenomenon to the uneven distribution of educational resources and the huge gap between urban and rural education, and believed that the existence of this phenomenon will lead to the solidification of all social classes, not conductive to social harmony and development. However, only a small number of rural students are admitted to top universities through the "Dream building program". The total number of rural children enrolled by Peking University and Tsinghua University this year is less than 2000, accounting for less than 20 percent of the total, which will hardly have a substantial impact on the fate of rural children. 
Secondly, those lucky ones who leap into the dragon gate are only as lucky as they seem. They are still faced with a huge gap between them and other children in terms of knowledge reserve and learning ability, waiting for them to overcome. Otherwise, gender inequality in education results is reflected in the employment rate and level of male and female graduates in higher education. According to statistics, under the same conditions, female graduates have only about $87.7 \%$ of male graduates[4]. Data provided by the Development of Chinese Children (2001-2002) shows that the enrollment rate of school-age children in China is $98.8 \%$, and the dropout rate of elementary schools has dropped from $2.77 \%$ in 1990 to $1.01 \%$ in 1997 . In fact, the dropout rate of girls is significantly higher than that of boys, accounting for about $70 \%$ of the total dropout rate[5].

The imbalance of educational resources also reflects the unfairness of education, which will affect social development. The lack of educational resources in rural areas leads to the low number and quality of education in rural areas, leading to the lower living standards of most rural populations. Migrant workers, disadvantaged groups of disabled people, lack of social security, and limited educational resources for their children.

Unequal distribution of educational resources will aggravate social polarization. Families with more money can afford better education, and their children are better educated and earn more. The annual income of those with higher education level is significantly higher than that of those with lower education level.

\section{REASONS FOR UNEVEN DISTRIBUTION OF EDUCATIONAL RESOURCES}

\section{1 uneven educational resources caused by regional differences}

Indeed, globalization creates losers as well as winners, and entails risks as well as opportunities. Globalization and rapid economic growth lead to inequality, both in the developed countries as well as the developing countries. China's economic growth has increased inequality between rural and urban populations, and between coastal and inland areas in China, which has disastrous consequences in the uneven distribution of educational resources,infrastructure and cultural resources. For instance,children who live in the Beijing or Shanghai not only have the best educational resources, but also can get into colleges with comparatively lower scores than other provinces. As the most economically developed cities in China, they have the highest quality educational resources. First of all, the local government will provide better public educational policies and resources. You can have a good learning experience in the public library, art museum, and science museum at a low expense or for free. These facilities are for children to broaden their horizons. Furthermore, more famous teachers and key schools give children advanced educational concepts. In addition, various private educational institutions or schools in the big cities are of better quality and popular among parents and students. Last but not least, living in bi cities can bring you in touch with more new things, exciting experiences in many aspects and have more possibilities. The educational concept shows openness, diversity and inclusiveness.

\subsection{Survey results and comparison between urban, suburban and rural}

The table below shows the difference in educational background of full-time teachers in ordinary high schools, middle schools and elementary schools. As is shown in the table, $90 \%$ of full-time teachers in ordinary senior high schools graduated from university. The proportion of graduate students in urban schools is slightly higher than that in suburban and rural schools, but the overall difference is the smallest. In the middle school stages,the proportion of full-time teachers in urban,suburban and rural schools with college graduates has increased to a certain extent, accounting for $10 \%, 20 \%$ and $24 \%$ respectively. In rural areas, $72.2 \%$ of elementary schools, $62.5 \%$ of middle schools and high schools are weak in education. In urban areas, $24.1 \%$ of elementary schools, $18.2 \%$ of middle schools and $27 \%$ of high schools are weak in education[2]. At the elementary level, the gap between urban and rural areas widens. Among the full-time teachers in rural elementary schools, $11 \%$ graduated from high school, $42 \%$ graduated from junior college and $37 \%$ graduated from university. For suburban elementary schools, the figures were $6 \%, 46 \%$ and $48 \%$. The figures for urban elementary schools were $2 \%, 30 \%$ and $66 \%$ [3]. In conclusion, in compulsory education stage 9 , especially in elementary school, the educational composition of full-time teachers in urban schools is higher than that in suburban schools, and that in suburban schools is higher than that in rural schools, which is an obvious imbalance. 


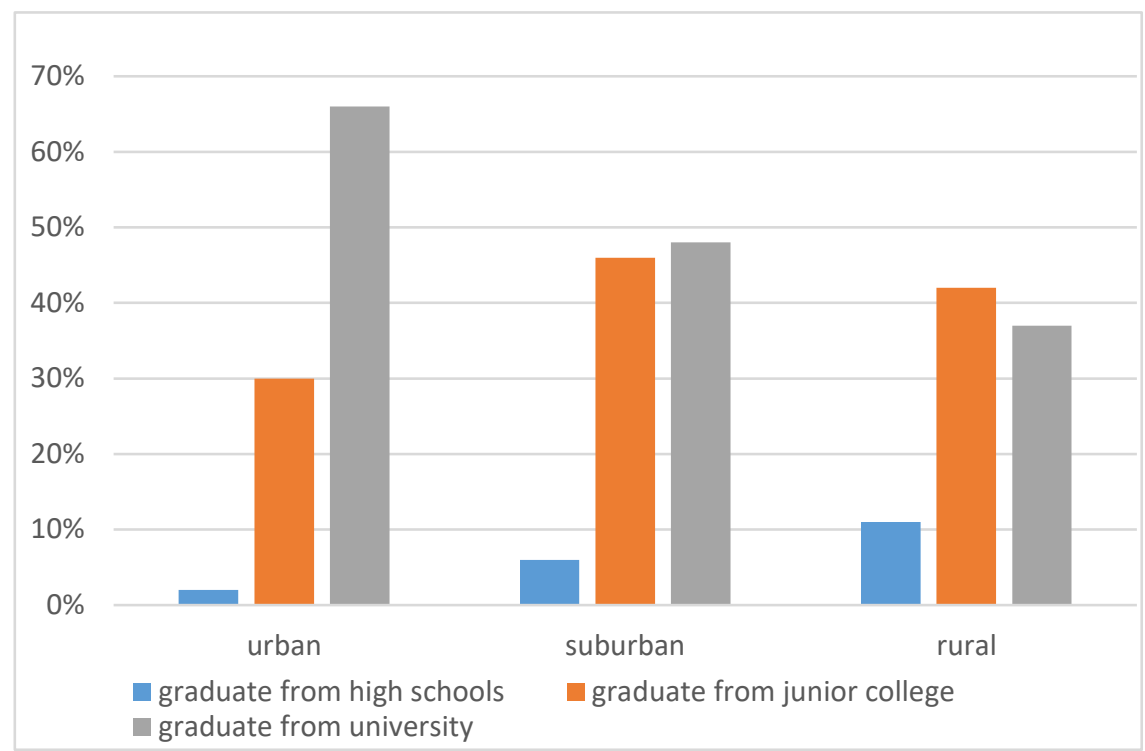

Figure 1: The difference of level of teachers between rural, urban and suburban areas

Source: According to China Education Statistical Yearbook-2016

On the basis of the comparison of urban and rural differences in student-teacher ratio, the same results we noted. The student-teacher ratio has always been an important index to measure the input of educational resources. The following table shows the differences in teacher ratios of elementary and secondary school students in urban areas, towns and villages. It can be seen that in ordinary senior high schools, the student-teacher ratio of urban, suburban and rural schools are 13.0, 14.3 and 13.7 respectively. At the middle school stage, the student-teacher ratio of urban, suburban and rural schools is 12.8,12.6 and 11.0 respectively, and the differences between urban and rural schools are not very obvious. However, in elementary schools, the ratio of students to teachers in urban, suburban and rural is 18.8,18.1 and 14.6 respectively. The ratio of students to teachers in urban schools is significantly higher than that in rural schools. This may be due to the relatively small scale of rural villages, resulting in the inefficient allocation of teacher resources.

Table 1. The teacher rate between urban, suburban and rural areas

\begin{tabular}{|l|l|l|l|}
\hline & High schools & Middle schools & Elementary schools \\
\hline urban and rural & 13.0 & 12.8 & 18.8 \\
\hline $\begin{array}{l}\text { Urban } \\
\text { integration areas }\end{array}$ & 13.4 & 12.7 & 18.5 \\
\hline suburban and rural & 14.3 & 12.6 & 18.1 \\
\hline $\begin{array}{l}\text { Urban } \\
\text { integration areas }\end{array}$ & 12.7 & 17.4 \\
\hline rural & 13.7 & 11.0 & 14.6 \\
\hline The national average & 13.7 & 12.4 & 17.1 \\
\hline
\end{tabular}

Source: According to China Education Statistical Yearbook-2016

We analyze the differences between urban and rural areas of hardware facilities in elementary and secondary schools through the indicators of teaching computers, multimedia classrooms and books. From the data in the following table, we can find an interesting phenomenon: no matter the number of computers for teaching per 10000 students, the number of multimedia classrooms per 10000 per student, the number of books per student, or the number of ordinary high schools, middle schools and elementary schools, urban areas are higher than rural areas. After comparing the data between urban, suburban and rural, it can be concluded that there is an urban-rural gap that China's long-term strategy of giving priority to urban development has led to the separation of education between urban and rural areas. Cities have more capacity to manage education and value it more. 
Table 2. Hardware facilities between urban, suburban and rural areas

\begin{tabular}{|c|c|c|c|c|c|}
\hline & & urban & suburban & Rural & $\begin{array}{l}\text { National } \\
\text { average }\end{array}$ \\
\hline \multirow{3}{*}{$\begin{array}{l}\text { Mathematics } \\
\text { computers }\end{array}$} & High schools & 2093.6 & 1333.7 & 1894.7 & 1708.9 \\
\hline & Middle schools & 1522.7 & 1252.6 & 1559.9 & 1392.8 \\
\hline & $\begin{array}{l}\text { Elementary } \\
\text { schools }\end{array}$ & 1065.1 & 848.6 & 956.4 & 951.4 \\
\hline \multirow{3}{*}{$\begin{array}{l}\text { Multimedia } \\
\text { classrooms }\end{array}$} & High schools & 317.7 & 222.6 & 297.2 & 269.7 \\
\hline & Middle schools & 255.0 & 216.8 & 262.5 & 237.0 \\
\hline & $\begin{array}{l}\text { Elementary } \\
\text { school }\end{array}$ & 200.6 & 170.7 & 191.0 & 186.5 \\
\hline \multirow[t]{3}{*}{ Books } & High schools & 42.0 & 32.3 & 40.0 & 37.1 \\
\hline & Middle schools & 32.9 & 33.1 & 41.9 & 34.4 \\
\hline & $\begin{array}{l}\text { Elementary } \\
\text { schools }\end{array}$ & 22.0 & 20.2 & 22.8 & 21.5 \\
\hline
\end{tabular}

Source: According to China Education Statistical Yearbook-2016

\subsection{The background of the students}

Parents with higher education level not only understand the importance of education, but also know more methods and approaches of education, which can provide more references for children in education. At the same time, unconsciously let children take themselves as an example, so that is easy for them to grow into outstanding people. Secondly, a good education needs a gigantic investment in education. Some parents hope their children can rely on education to master more ability, so as to obtain more life value and wealth.Therefore, the best resource is a paid resource, which needs to pay the highest cost. In reality, parents who want to enter elite schools will eventually test their financial resources and connections. School district housing and household registration have become a barrier, which effectively separates parents in and out of the room. Parents with vast wealth often tend to pay for children's education, such as early education and programming courses. The high tuition fees and better education investment are inevitable[8]. However, parents are willing to afford expensive tuition as long as they finally get all A. Apart from that, rich parents can easily afford good teachers, key schools and various hobbies for their children, which help them to be outstanding, while poor parents can only provide food, clothing and compulsory education for their children[6]. In addition,according to the 2019 Domestic Family and Children's Education Investment Survey conducted by the Ministry of Education of China, families' annual spending on children's education has mainly been $12,000-24,000$ yuan and 24,000-36,000 yuan, accounting for $22.4 \%$ and $21.7 \%$ respectively. Besides, according to a "China's Better Life Survey" launched by CCTV financial program Center, $31.3 \%$ of parents want to increase spending on "education and training" in 2021, ranking third in the total consumption options. While parents sigh and feel deeply, they also say that the real cost can be more than that.

Different horizons of parents have an influence on children's education level. In fact, some parents in rural areas believe that studying is useless because they have worked so hard and saved so much money to send their children to college, but they still don't have a good job after graduation. Thus, they would rather let their children work earlier. Nevertheless, the rich have a wider vision and see more of the market. They let their children study not simply for the purpose of finding a job in the future, but more for the cultivation of their children's ability. Even if their children cannot find a good job, they still grasp a lot of opportunities and possibilities in their life.

\section{SOME MEASURES TO BALANCE EDUCATIONAL RESOURCES}

\subsection{Increase the investment in education}

The imbalance in the development of education between urban and rural areas is caused by the imbalance in the allocation of educational resources 
between urban and rural areas. Thus, the lack of financial investment and uneven distribution is the biggest obstacles to the development of urban and rural education in China. In order to change the position of education in rural areas, it is important that the national finance increase the overall investment in education and the funds for education should be appropriately titled towards schools in rural areas. It is necessary to advocate in various cities to establish urban and rural education investment systems, expand the individual educational funds and education market funding in order to guarantee rural students have the most basic education funds resources and promote educational equality.

\subsection{Hire more teachers}

Implement the policy of teacher mobility. To ensure the balanced educational resources of the school, we encourage peer mentoring and part-time work between schools with a decent salary. Improving teachers' salary and treatment is conductive to improving teachers' material and cultural life, which is the embodiment of teachers' personal value and social value. The governments need to establish allowance and benefits for rural teachers, accelerate the construction of dormitories for rural teachers, medical care and old-age care are included. Another key measure is to improve the overall quality of teachers, increasing the investment in teacher training[7]

College students and excellent teachers are encouraged to volunteer in education backward areas. Enrich the reserve and training of educational talents, and appropriately raise the salary of teachers. Cultivate a large number of teachers who can teach and teach well in the new era.

\subsection{Improve education infrastructure}

Improve the rural education infrastructures construction, change the situation of its resource allocation is insufficient. The local government should strengthen rural development, raise families' incomes, and ensure that all rural children can receive an education. What's more, the educational systems should be improved and optimized. Strengthen support for education in rural areas and promote equal allocation of compulsory education resources between urban and rural areas. Educational institutions, development and reform departments, finance departments, human resources and social security departments should work in close coordination. They should accelerate the establishment of a responsibility mechanism to promote the balanced development of urban and rural compulsory education. And they need to cope with that effective inspections in place, rigorous assessments, clear rewards and punishments and open accountability.
At the present stage, it is necessary for governments to take measures from the system and policy to fulfill their responsibilities to promote the development of rural compulsory education[9]. Only in this way, can we maximize the balanced allocation of educational resources and educational fairness.

\section{CONCLUSION}

This paper examines the manifestation, causes and solutions of the distribution of uneven educational resources. We studied the allocation of compulsory educational resources in urban, suburban and rural areas in China from three aspects: education funds, experienced teachers and qualified technologies. Those are attributed to economic disparities, while it continues to perpetuate social and economic inequality. The paper finds out that the background, earnings and educational level of their parents, their gender, social class, and political participation contribute to the uneven distribution of educational resources. And it is difficult to eradicate with different causes that are deeply rooted in history, society and culture. Based on the analysis and comparison of the current situation of the development of education resources in China, we can draw the conclusion that the government's responsibilities in balancing allocation of educational resources should not be underestimated. It is necessary to increase the government's investment in special funds for schools, ensure the educational development of poor areas in legal form, attach importance to the experience and capability of teachers and improve educational infrastructures to realize education equality, ensure that every child enjoys equal rights to education and promote the balanced development of education between urban ,suburban and rural areas.

\section{REFERENCES}

[1]Zhang Xiaoran, "It is difficult for students from poor families to attend Peking University to cover the uneven distribution of educational resources"

[2]Zhang Hui, The current situation, causes and countermeasures of unfair inter-school resource allocation in Compulsory education in China

[3]Zhang Fangfang, Study on the Balance Allocation of Compulsory Education Resources---taking urban and rural Education in Jiangsu Province as an example

[4]Liao Keling, analysis of the Reasons and Countermeasures of female College Students' Employment Difficulties $[\mathrm{J}]$, Education and Occupation, 2006 (1)

[5]Yu Wei, Hu Jiao, Gender Inequality Compulsory Education in China $[\mathrm{J}]$. Journal of Normal 
University (Philosophy and Social Sciences Education), 2005, (5)@ Conducian Ya

[6]Lee, Chungmei; Gary Orfield (2005). "Why Segregation Matters: Poverty and Education Inequality". The Civil Rights Project. Harvard University: $1-47$

[7]Haycock, Kafi (2001). "Closing the Achievement Gap". Helping All Students Achieve. 58: 6-11

[8]Farkas, George (2006). "How Educational Inequality Develops". National Poverty Center. Working Paper Series: 1-50

[9]Ferreira, Francisco; Gignoux, Jeremie (2014). "The Measurement of Educational Inequality: Achievement and Opportunity". World Bank Economic Review. 28 (2): 210-246 